Article

\title{
Biological Activity and Safety of Tripterygium Extract Prepared by Sodium Carbonate Extraction
}

\author{
Wei Fang ${ }^{1, \dagger}$, Fan Peng ${ }^{1, \dagger}$, Tao Yi ${ }^{2}$, Cong Zhang ${ }^{1}$, Chunxi Wan ${ }^{1}$, Huibi Xu ${ }^{1,2}$, \\ Christopher Waikei Lam ${ }^{1,2, *}$ and Xiangliang Yang ${ }^{1,2, *}$
}

1 College of Life Science and Technology, Huazhong University of Science and Technology, Wuhan 430074, China

2 State Key Laboratory for Quality Research in Chinese Medicine, Macau Institute for Applied Research in Medicine and Health, Macau University of Science and Technology, Macau, China

$\dagger$ These authors contributed equally to this work.

* Authors to whom correspondence should be addressed; E-Mails: wklam@must.edu.mo (C.W.L.); yangxl@mail.hust.edu.cn (X.Y.); Tel.: +86-27-8779-4520 (X.Y.); Fax: +86-27-8779-4517 (X.Y.).

Received: 3 August 2012; in revised form: 6 September 2012 / Accepted: 7 September 2012 /

Published: 17 September 2012

\begin{abstract}
The commercial preparation named "Tripterygium glycosides" prepared by column chromatography has been used for the treatment of inflammatory and autoimmune diseases with significant efficacy but concurrent toxicity. The aim of this study was to reduce the toxicity of Tripterygium extracts, using cytotoxicity and anti-inflammatory activity of the three principal active components of Tripterygium wilfordii Hook. F. (TWHF) as guiding parameters. Column chromatography was replaced by sodium carbonate extraction for removing the acidic compounds and enriching epoxyditerpenoids and alkaloids in the extract. Results showed that the therapeutic index $\left(\mathrm{IC}_{50} / \mathrm{EC}_{50}\right)$ on murine macrophage Raw 264.7 cells and rat mesangial HBZY-1 cells of the extract prepared by sodium carbonate extraction was significantly higher than that of Tripterygium glycosides ( 0.8 and 5.2 vs. 0.3 and 2.6, $p<0.05$ ), while its cytotoxicity on human liver HL7702 cells was significantly lower $(14.5 \pm 1.4$ vs. $6.8 \pm 0.9, p<0.05)$. Further acute oral toxicity experiments showed that the $\mathrm{LD}_{50}$ value of this extract was $1,210 \mathrm{mg} / \mathrm{kg}$ compared to $257 \mathrm{mg} / \mathrm{kg}$ for Tripterygium glycosides. All the above results suggest that Tripterygium extract prepared by sodium carbonate extraction may represent a potentially optimal source of medicine with good therapeutic index.
\end{abstract}


Keywords: Tripterygium wilfordii Hook. F.; active components; sodium carbonate extraction; toxicity

\section{Introduction}

Tripterygium wilfordii Hook. F. (TWHF) is a woody vine widely distributed in eastern and southern China. Known in Chinese language as "Lei Gong Teng" (Thunder God Vine), this plant has a long history of therapeutic use in traditional Chinese Medicine (TCM), with efficacies in expelling wind, removing dampness, promoting blood circulation, freeing channels, trimming bruises, and as a hemagogue [1]. Commercial preparations of TWHF have been commonly used for the treatment of inflammatory and autoimmune diseases, such as rheumatoid arthritis, systemic lupus erythematosus, nephritis and psoriasis [2-5].

TWHF fractions for research and clinical studies have been extracted using different solvents: water, ethyl acetate, ethanol, and chloroform-alcohol, consequently, these extracts have different compositions and biological activities. However, extracts also manifested recurrent toxicity symptoms, such as diarrhea, leucopenia, thrombocytopenia, skin pigmentation, liver and renal injuries, and infertility [6]. Column chromatography of the ethyl acetate extract yields Tripterygium glycosides of reduced toxicity [7]. Wilforlide A, one of the triterpenoids, has been chosen as the index for assessing Tripterygium glycoside preparations. The content of this compound in TWHF is however minute $(<0.1 \mathrm{mg} / \mathrm{g})$. On the other hand, it has been generally recognized that triptolide, celastrol and wilforine are representative compounds in TWHF. Their contents in Tripterygium glycosides have not been investigated and the relationship of their therapeutic efficacy and toxicity has remained unclear. We studied the cytotoxicity and anti-inflammatory activity of these three principal terpenoids as the target compounds.

In addition, column chromatography is a tedious fractionation procedure with poor reproducibility affecting the yield of active compounds [8]. Guided by assessment of cytotoxicity and anti-inflammatory activity of the active parts, our objective was also to develop a simple and reproducible method for extraction of Tripterygium for simultaneously optimizing biological activity and reducing toxicity.

\section{Results and Discussion}

\subsection{Cytotoxicity and Anti-inflammatory Activity of Triptolide, Celastrol and Wilforine}

Toxicity and anti-inflammatory activity of the compounds were assessed initially by their $\mathrm{IC}_{50}$ (dosage causing 50\% cell death) and $\mathrm{EC}_{50}$ (dosage inhibiting 50\% NO and $\mathrm{TNF}-\alpha$ production) values. Since the active components of TWHF always possess toxicity, the ratio of cytotoxicity to bioactivity $\left(\mathrm{IC}_{50} / \mathrm{EC}_{50}\right)$ was used for further assessing safety and therapeutic efficacy.

As shown in Table 1, triptolide exhibited a larger therapeutic window than celastrol on murine mesangial HBZY-1 cells $\left(\mathrm{IC}_{50} / \mathrm{EC}_{50}>10\right)$. This suggests that triptolide may be more efficacious and safer than celastrol for treating nephritis. Wilforine showed no obvious activity under the experimental conditions on both renal and immune cells. We consider alkaloids having moderate biological activity 
but can reconcile the toxic effect of the diterpenes, making the combination safer. The alkaloid fraction should therefore be retained.

Table 1. Cytotoxicity and anti-inflammatory activity of triptolide, celastrol and wilforine.

\begin{tabular}{|c|c|c|c|c|c|c|}
\hline \multirow[b]{2}{*}{ Sample } & \multicolumn{2}{|c|}{ HBZY-1 cells } & \multirow[b]{2}{*}{$\mathrm{IC}_{50} / \mathbf{E C}_{50}$} & \multicolumn{2}{|c|}{ RAW264.7 cells } & \multirow[b]{2}{*}{$\mathrm{IC}_{50} / \mathbf{E C}_{50}$} \\
\hline & $\begin{array}{c}\text { Cytotoxicity } \\
\text { IC }_{50}(\mathrm{nmol} / \mathrm{L})\end{array}$ & $\begin{array}{c}\text { Anti-inflammatory } \\
\text { activity } \mathrm{EC}_{50}(\mathrm{nmol} / \mathrm{L})\end{array}$ & & $\begin{array}{c}\text { Cytotoxicity } \\
\text { IC }_{50}(\mathrm{nmol} / \mathrm{L})\end{array}$ & $\begin{array}{c}\text { Anti-inflammatory } \\
\text { activity } \mathrm{EC}_{50}(\mathrm{nmol} / \mathrm{L})\end{array}$ & \\
\hline Triptolide & $230.3 \pm 9.9$ & $20.7 \pm 2.1$ & 11.1 & $40.2 \pm 2.7$ & $25.0 \pm 4.4$ & 1.6 \\
\hline Celastrol & $3715 \pm 342$ & $1040 \pm 40$ & 3.6 & $360 \pm 41$ & $260.3 \pm 20.9$ & 1.4 \\
\hline Wilforine & nd & nd & nd & nd & nd & nd \\
\hline
\end{tabular}

nd $=$ not detected.

\subsection{Quantification of Active Compounds in TWHF Extract}

Many terpenoids with strong biological activities have been isolated from TWHF extracts. They comprise sesquiterpenes, diterpenes and triterpenes [9]. Celastrol, a quinonemethide triterpene, triptolide, a diterpenoid triepoxide, and wilforine, a sesquiterpene alkaloid, are representative compounds [9-11]. Therefore the contents of celastrol, triptolide and wilforine were measured to study the variability of active components in different extracts.

In order to reduce toxicity, the ethyl acetate extract was further extracted with sodium carbonate solution for removing the acidic components, in particular the triterpenoid celastrol, and enriching alkaloids and diterpenoids which are the two principal groups of active components of TWHF. Again, the rationale of this further extraction was that firstly, the liver toxicity of the alkaloids is much lower than those of the diterpenoids and secondly, celastrol is more nephrotxic and can cause glomerulo-nephritis and -proteinuria.

The weights and contents of celastrol, triptolide, and wilforine in the various extracts are shown in Table 2. Compared to the ethanol extract, contents of these three compounds increased approximately 2-fold in the EtOAc extract (1.4 vs. 0.71, 0.032 vs. 0.015, and $2.4 v s .1 .1 \%$ ), and extraction yields were 89, 98.8, 100.1\%, respectively. Ethyl acetate may therefore be a good solvent for extracting active compounds from the ethanol extract. In the extraction with aqueous sodium carbonate solution, the acidic component celastrol was distributed mainly in the alkaline aqueous layer at 1.7 times higher levels than the EtOAc extract (2.4 vs. 1.4\%), while the neutral component triptolide and the weakly basic component wilforine were concentrated in the ethyl acetate layer, where their contents were 1.6 and 1.8 times higher than those in the EtOAc extract ( 0.051 vs. 0.032 and $4.4 v s .2 .4 \%$ ), respectively.

Table 2. Weights and contents of celastrol, triptolide and wilforine in different extracts.

\begin{tabular}{lcccc}
\hline \multirow{2}{*}{ Sample } & \multicolumn{3}{c}{ Content (\%) of active compound } & \multirow{2}{*}{ Weight (mg) } \\
\cline { 2 - 4 } & triptolide & celastrol & wilforine & \\
\hline Ethanol extract & 0.015 & 0.7 & 1.1 & $1,000.0$ \\
EtOAc extract & 0.032 & 1.4 & 2.4 & $454.5^{* *}$ \\
Extract 1 & 0.051 & 0.09 & 4.4 & $234.0 * *$ \\
Extract 2 & $\mathrm{nd}^{*}$ & 2.4 & $\mathrm{nd}$ & $184.6^{* *}$ \\
Tripterygium glycosides & 0.92 & $\mathrm{nd} *$ & 1.7 & - \\
\hline
\end{tabular}

$*$ not detected; $* *$ Based on the starting weight of ethanol extract at $1,000.0 \mathrm{mg}$. 


\subsection{Cytotoxicity and Anti-Inflammatory Activity of TWHF Extracts}

Table 3 shows the cytotoxic activities of different extracts as assessed by the MTT assay. They provide information about the initial toxicity of extracts on different cell lines. It can be seen that $\mathrm{IC}_{50}$ values of the EtOAc extract were the lowest among all extracts, confirming that this extract had the highest toxicicty. With sodium carbonate extraction, toxicity was greatly reduced, especially on human HL7702 liver cells $(p<0.05)$. Compared to the EtOAc extract, the toxicity of Extract 1 (containing mainly neutral and weakly basic compounds) had reduced about three times (4.9 to 14.5), and that of Extract 2 (containing mainly acidic components) about eight times (4.9 to 33.3) on HL7702 cells. The concentrations of active compounds in EtOAc extract were less than those in Extract 1 (0.032 vs. 0.051 and 2.4 vs. $4.4 \%$ for triptolide and wilforine) and Extract 2 (1.4 vs. 2.4\% for celastrol). Toxicity may therefore be influenced by the interaction of multiple components in TWHF. Removal of some compounds may reduce the side effects of Tripterygium preparations.

Table 3. Cytotoxic and anti-inflammatory activities of different extracts.

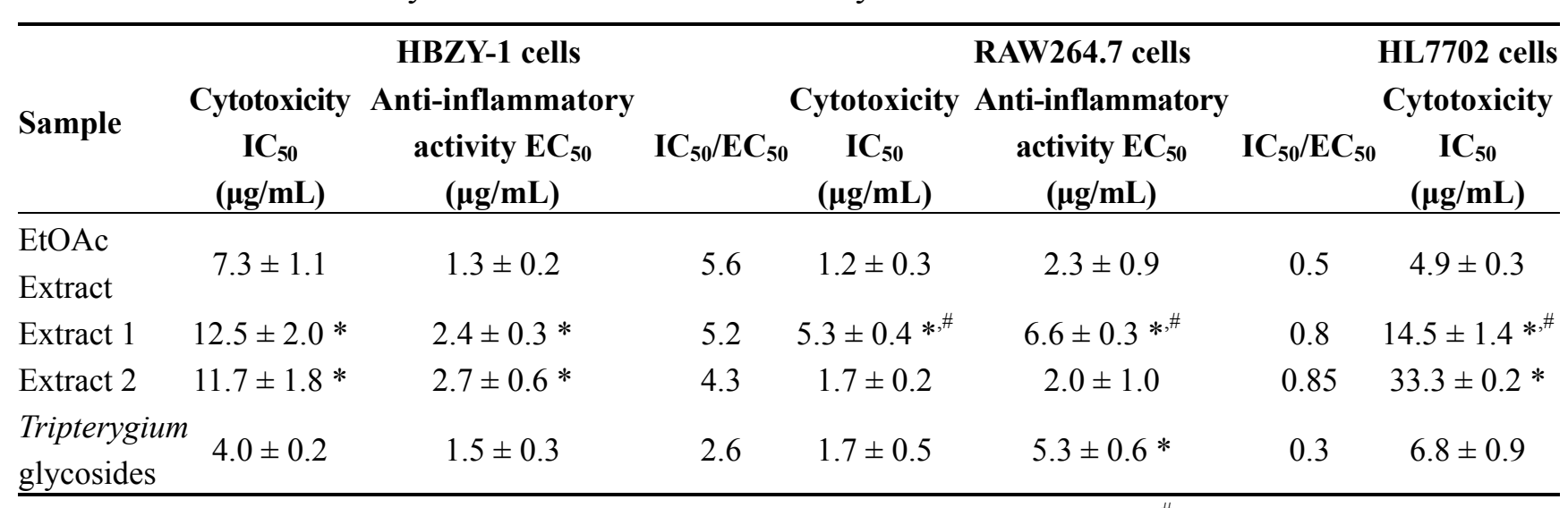

Compared to EtOAc extract: ${ }^{*} p<0.05$, Compared to Extract 2: ${ }^{\#} p<0.05$.

Compared to the EtOAc extract, toxicity of Extract 1 on RAW264.7 cells was reduced about four times (1.2 to 5.3, $p<0.05)$, and that of Extract 2 was comparable (1.2 vs. 1.7). The content of celastrol in Extract 1 was lower than those of the EtOAc extract and Extract 2 (0.09 vs. 1.4 and 2.4). Therefore celastrol should be viewed as the principal toxic compound in TWHF that was removed for reducing the toxicity of TWHF extracts [12].

All extracts showed significantly dose-dependent anti-inflammatory activity, as assessed by their in vitro inhibition of LPS-induced TNF- $\alpha$ from macrophages and NO production from rat mesangial cells. As shown in Table 3, $\mathrm{EC}_{50}$ values of the EtOAc extract was lower than those of Extract 1 and Extract 2. This demonstrated that the EtOAc extract was biologically the most active one. Such a finding is in agreement with the cytotoxic assessment, which can be explained by the presence of compounds, such as diterpenoid lactone epoxides [13] and celastrol [14], not only having significantly anti-inflammatory and immunosuppressive activity, but also severe toxicity. The biological activity of TWHF extracts is related to its toxicity, it is important to balance the two effects therapeutically [15].

With regard to the contents of active compounds in Tripterygium glycosides and Extracts 1, Table 2 shows that the contents of wilforine and triptolide in Extract 1 were 4.4 and $0.051 \%$, respectively, while those in Tripterygium glycosides were 1.70, and $0.92 \%$, respectively. Wilforine in Extract 1 was 
therefore 2.6 times more abundant than that in Tripterygium glycosides, while the content of triptolide was only an 1/18 fraction. Even with such large differences between the contents of the two active compounds, the anti-inflammatory activities of Extract 1 and Tripterygium glycosides were comparable, and the therapeutic index $\left(\mathrm{IC}_{50} / \mathrm{EC}_{50}\right)$ of Extract 1 was higher than that of Tripterygium glycosides on Raw 264.7 and HBZY-1 cells. Furthermore, the composition of Extract 1 (containing more alkaloids) suggested that its toxicity should be lower than that of Tripterygium glycosides.

\subsection{Assessment of Extract 1 for Acute Toxicity}

The experimental animals showed obvious toxicity from oral administration of Extract 1 manifesting slow movements, diarrhea and respiratory depression. The high-dose group died within $24 \mathrm{~h}$, and all dead mice showed significant gastrointestinal toxicity, intestinal necrosis, black liver and spleen, with toxicity being more severe in male than female mice. The $\mathrm{LD}_{50}$ of Extract 1 was $1,210 \mathrm{mg} / \mathrm{kg}$, and the $95 \%$ confidence interval $(\mathrm{CI})$ was $1,098-1,322 \mathrm{mg} / \mathrm{kg}$. As reported in the literature, $\mathrm{LD}_{50}$ of the Tripterygium glycosides tablet is $257 \mathrm{mg} / \mathrm{kg}(\mathrm{CI}=227-287 \mathrm{mg} / \mathrm{kg})$ [16]. Thus our study showed that with sodium carbonate extraction, the toxicity of Tripterygium extract was greatly reduced.

\section{Experimental}

\subsection{Materials}

All solvents were of HPLC grade, purchased from Merck Serono Co. Ltd. (Darmstadt, Germany). Triptolide was purchased from the National Institute for Food and Drug Control (Beijing, China), and celastrol from Zelang Pharmaceutical Technology Co. Ltd. (Nanjing, China). Wilforine was isolated and identified by our laboratory. The purity of these three terpenoids was more than $98 \%$ as determined by high performance liquid chromatography (HPLC).

RPMI-1640, DMEM/high glucose, fetal bovine serum (FBS), streptomycin sulphate and ampicillin, trypsin, ethylenediamine tetraacetic acid (EDTA), L-glutamate and non essential amino acid were purchased from Gibco (Invitrogen Co., Burlington, ON, Canada), Lipopolysaccharide (LPS; Samonella minnesota), dimethyl sulfoxide (DMSO), 3-(4,5-dimethyl-2-thiazolyl)-2,5-diphenyl2H-tetrazolium bromide (MTT), sodium lauryl sulfonate (SDS) and Griess reagent were purchased from Sigma-Aldrich Co. (St. Louis, MO, USA). Dimethylformamide (DMF), N-(1-naphthyl)ethylenediamine dihydrochloride and 4-aminobenzenesulfonic acid were purchased from Sinopharm Chemical Reagent Co. Ltd. (Shanghai, China). Recombinant rat TNF- $\alpha$, purified anti-rat/mouse TNF- $\alpha$ (clone TN3-9,10Ab), biotin-conjugated anti-rat/mouse TNF- $\alpha$ (poly clone, 20Ab), Super AquaBlue ELISA substrate and Avidin-HRP were purchased from eBioscience Co. (San Diego, CA, USA).

\subsection{Assessment of Cytotoxicity Using MTT Assay for Triptolide, Celastrol and Wilforine}

\subsubsection{Cell Culture and Treatment}

The human liver HL-7702 cell line (ATCC CRL-11731) and murine macrophage-like cell line RAW 264.7 (ATCC TIB-71), both purchased from Wuhan Boster Bio-engineer Co. Ltd. (Wuhan, China), were maintained in RPMI-1640 medium supplemented with 10\% (v/v) FBS, 1\% (w/v) L-glutamate, 1\% (w/v) 
non-essential amino acid, $0.01 \%(\mathrm{w} / \mathrm{v})$ ampicillin and $0.05 \%(\mathrm{w} / \mathrm{v})$ streptomycin sulphate (RPMI-1640 complete medium). The rat mesangial cell line HBZY-1 (CCTCC GDC-124), purchased from China Center for Type Culture Collection (Wuhan, China), was maintained in Dulbecco's modified Eagle's medium (DMEM) supplemented with 10\% (v/v) FBS, 1\% (w/v) L-glutamate, 1\% (w/v) non essential amino acid, 0.01\% (w/v) ampicillin and $0.05 \%(\mathrm{w} / \mathrm{v})$ streptomycin sulphate (DMEM complete medium). All cells were incubated at $37{ }^{\circ} \mathrm{C}$ in air atmosphere enriched with $5 \%(\mathrm{v} / \mathrm{v}) \mathrm{CO}_{2}$. HL-7702 cells were subsequently subcultured using $0.25 \%(\mathrm{w} / \mathrm{v})$ trypsin-1mM EDTA with gentle aspiration to form a single cell suspension, while RAW 264.7 cells were subcultured using cellular scraper to form a single cell suspension. At $80 \%$ confluence, cells dispersed in RPMI-1640 or DMEM complete medium to a final cell concentration of $2 \times 10^{5}$ cells $/ \mathrm{mL}$.

\subsubsection{MTT Assay}

Assessment of cytotoxic activity was based on the reduction of MTT by the mitochondrial dehydrogenase of viable cells to give a blue formazan product, which can be measured spectrophotometrically. Briefly, cells were seeded in a 96-well plate at density $5 \times 10^{3}$ cells per well with $180 \mu \mathrm{L}$ complete RPMI medium and incubated for $12 \mathrm{~h}$ at $37{ }^{\circ} \mathrm{C}$ for adherence. $20 \mu \mathrm{L}$ of samples (dissolved in DMSO at various concentrations), blank control (water) and negative control (2\% (w/v) DMSO) were mixed into the well, and cells were incubated at $37{ }^{\circ} \mathrm{C}$ for $72 \mathrm{~h}$. MTT solution $(5 \mathrm{mg} / \mathrm{mL})$ was added to each well at $5 \mu \mathrm{L} /$ well), and the plate was incubated for another $12 \mathrm{~h}$. The supernatant was carefully removed and replaced with $100 \mu \mathrm{L}$ of cell lysis buffer [40\% (w/v) SDS, 50\% (w/v) DMF and $50 \%$ water, $\mathrm{pH}=4.7]$, and the plate agitated to dissolve the formazan crystals. The absorbance of the dissolved formazan product was measured at $492 \mathrm{~nm}$ in a microplate reader. Cell viability was calculated using the following formula: $\%$ viability $=$ absorbance of sample/absorbance of control $\times 100$.

\subsection{Anti-inflammatory Assays for Triptolide, Celastrol and Wilforine}

\subsubsection{Measurement of Nitrite}

HBZY-1 cells were seeded into a 48-well culture plate at density of $5 \times 10^{4}$ cells per well with $400 \mu \mathrm{L}$ of DMEM complete medium, and incubated for $12 \mathrm{~h}$. The complete medium was replaced with $360 \mu \mathrm{L}$ serum-free DMEM medium, $20 \mu \mathrm{L}$ of sample (dissolved in DMSO at various concentrations), blank control (water) and negative control $(2 \% \mathrm{w} / \mathrm{v}$ DMSO). Cells were then stimulated with $20 \mu \mathrm{L}$ LPS (100 ng/mL) for $48 \mathrm{~h}$. The presence of nitrite, a stable oxidized product of nitric oxide (NO) from anti-inflammatory activity of the cells against LPS, was determined in cell culture medium using Griess reagent. In this measurement, $50 \mu \mathrm{L}$ supernatant was removed and reacted with $50 \mu \mathrm{L}$ Griess reagent in a 96-well plate, followed by spectrophotometric measurement at $531 \mathrm{~nm}$ on a microplate reader. The cell viability was determined using MTT assay.

\subsubsection{ELISA}

RAW 264.7 cells were seeded into a 48 -well culture plate at $5 \times 10^{4}$ cells per well with $360 \mu \mathrm{L}$ of RPMI-1640 complete medium, and incubated for 12 h. $20 \mu \mathrm{L}$ of sample (dissolved in DMSO at various concentrations), blank control (water) or negative control ( $2 \% \mathrm{w} / \mathrm{v}$ DMSO) was added into the 
well, and cells were stimulated with $20 \mu \mathrm{L}$ LPS $(20 \mathrm{ng} / \mathrm{mL})$. The supernatant of each well was collected after $12 \mathrm{~h}$ and stored at $-20^{\circ} \mathrm{C}$.

Double-antibody "sandwich" ELISA was used to determine TNF- $\alpha$ concentration in the samples. Briefly, Nunc MaxiSorp flat-bottom 96-well plate (eBioscience) was coated with primary antibody at $4{ }^{\circ} \mathrm{C}$ overnight, and the plate was blocked with blocking buffer (1\% BSA, $5 \%$ sucrose, $0.05 \% \mathrm{NaN}_{3}$ in PBS ( $\mathrm{pH}=7.2-7.4, \mathrm{Ca}^{2+}$ and $\mathrm{Mg}^{2+}$ free) at room temperature for at least $2 \mathrm{~h}$. After washing 5 times with wash buffer (PBS with $0.05 \%$ Tween-20), samples were added into the appropriate wells, and the plate was incubated at $4{ }^{\circ} \mathrm{C}$ overnight. Secondary antibody (diluted with Assay Buffer (PBS with $0.05 \%$ Tween-20 and $0.1 \%$ BSA) was added into each well after the plate was washed with wash buffer. After $1 \mathrm{~h}$ at room temperature, the plate was washed again, Avidin-horse reddish peroxidase (HRP) solution was added to all the wells, and protected from light at room temperature for $1 \mathrm{~h}$. After washing, Super AquaBlue ELISA substrate Solution was added to each well. The plate was incubated at room temperature for $30 \mathrm{~min}$, and read at $405 \mathrm{~nm}$.

\subsection{Preparation of Plant Extracts}

T. wilfordii roots were collected from a Good Agricultural Practice (GAP) site in Taining County of Fujian province in January 2010 and identified by Professor Xiaochuan Ye of Hubei University of Chinese Medicine. Voucher specimens were deposited in Institute of Materia Medica of Huazhong University of Science and Technology with reference numbers THWF 1001151.

Roots $(16 \mathrm{~kg})$ were cut into small pieces and dried at $50{ }^{\circ} \mathrm{C}$, then ground into $40-60$ mesh powder. The powder was extracted three times by refluxing with $95 \%$ aqueous ethanol $(80 \mathrm{~L})$ for $2 \mathrm{~h}$. The ethanol solvent was filtered and dried by evaporation under reduced pressure to yield the Ethanol extract (380 g). The Ethanol extract (200 g) were extracted three times by refluxing with ethyl acetate ( $2 \mathrm{~L}$ ) for $1 \mathrm{~h}$. The ethyl acetate solvent was then filtered and evaporated under reduced pressure to yield the EtOAc extract. This extract (90 g) was dissolved in ethyl acetate, extracted with 5\% sodium carbonate solution twice, and then washed with water to neutral $\mathrm{pH}$, and evaporated under reduced pressure to yield Extract 1. Sodium carbonate solution and washing water were combined, the $\mathrm{pH}$ of the mixture was adjusted to 3 with $2 \%$ hydrochloric acid, and extracted three times with ethyl acetate. The ethyl acetate layer was evaporated under reduced pressure to yield Extract 2 (Figure 1). The Tripterygium glycoside medicine (100 tablets, Lot No.20100302) was ground into power and extracted three times by refluxing with methanol $(100 \mathrm{~mL})$ for $1 \mathrm{~h}$. The methanol solvent was filtered and then dried by evaporation under reduced pressure to yield Tripterygium glycoside extract.

\subsection{Measurement of Triptolide, Celastrol and Wilforine in the Extracts}

\subsubsection{Triptolide}

Triptolide content of the crude extract was determined by HPLC, as described previously [17], except with some slight modifications. The extract $(0.2 \mathrm{~g})$ was dissolved in chloroform $(5 \mathrm{~mL})$ and loaded on a column packed with $2.0 \mathrm{~g}$ neutral aluminum oxide $\left(\mathrm{Al}_{2} \mathrm{O}_{3}\right)$. Elution was with ethyl acetate $(20 \mathrm{~mL})$. The eluate was evaporated under reduced pressure, and redissolved in methanol $(5.0 \mathrm{~mL})$. Samples were filtered through a $0.22 \mu \mathrm{m}$ membrane filter for HPLC analysis, which was carried out on 
an Agilent 1100 HPLC system equipped with an Agilent G1314A UV detector (Agilent Technologies, Waldbronn, Germany) and Agilent Software. The separation was performed at $25{ }^{\circ} \mathrm{C}$ using a $250 \mathrm{~mm} \times 4.6 \mathrm{~mm}$, i.d., $5 \mu \mathrm{m}$, ZORBAX Eclipse Plus C18 with a Agilent guard cartridge. The mobile phase was composed of $\mathrm{MeOH}-\mathrm{H}_{2} \mathrm{O}$ at 42:58 (v/v). The injection volume was $10 \mu \mathrm{L}$, and detection was carried out at $210 \mathrm{~nm}$. In order to quantify the amount of triptolide in extracts, calibration curves were prepared with the standards dissolved in methanol. The calibration curves showed good linearity over $2.6-52.0 \mu \mathrm{g} / \mathrm{mL}$.

Figure 1. Protocol for preparation of different TWHF extracts.

Tripterygium wilfordii roots

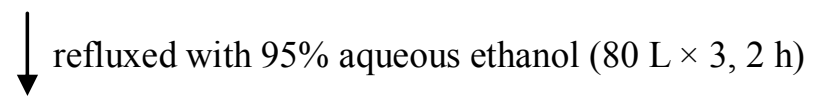

Ethanol extract

$\downarrow$ extracted with ethyl acetate

EtAc extract

dissolved in ethyl acetate, extracted with $5 \% \mathrm{Na}_{2} \mathrm{CO}_{3}$

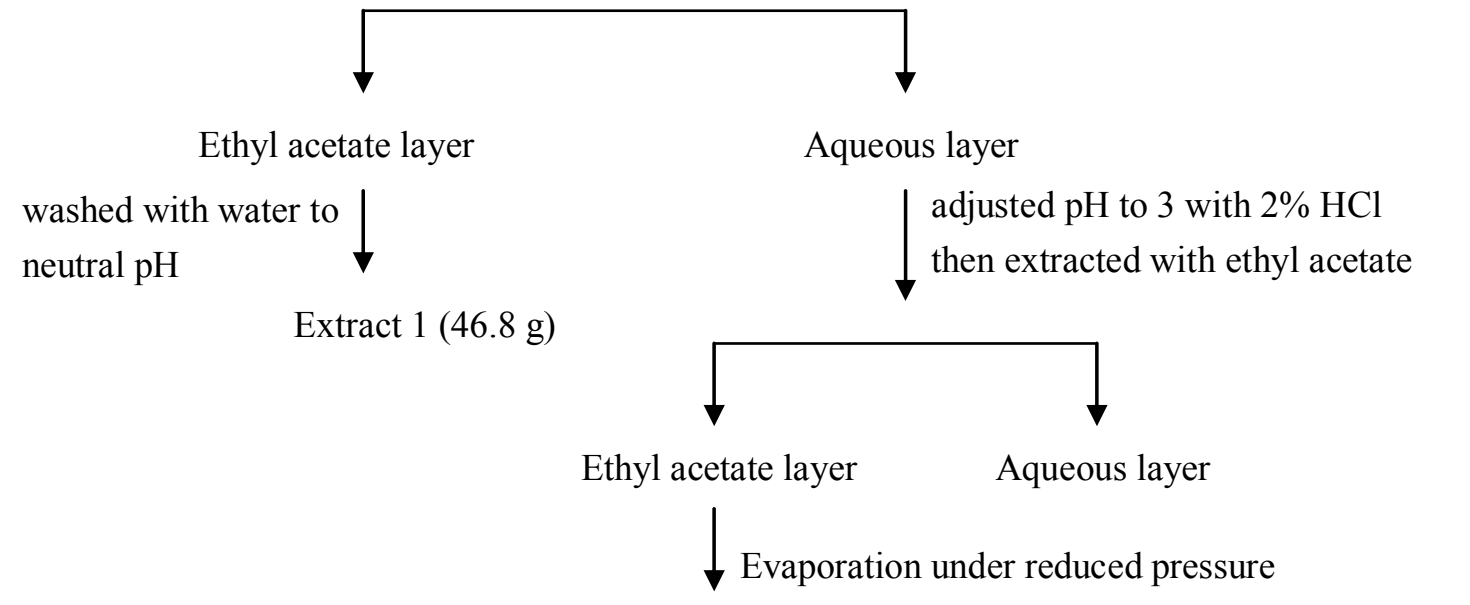

Extract $2(37.0 \mathrm{~g})$

\subsubsection{Celastrol}

Celastrol content of the crude extract were determined by HPLC, as described previously with some modifications [18]. Extract $(0.1 \mathrm{~g})$ was dissolved in chloroform $(5 \mathrm{~mL})$ and loaded on a column packed with $2.0 \mathrm{~g}$ silica, Elution was with ethyl acetate $(20 \mathrm{~mL})$. The eluate were evaporated under reduced pressure, and re-dissolved in methanol $(10.0 \mathrm{~mL})$. Samples were filtered through a $0.22 \mu \mathrm{m}$ membrane filter for HPLC, which was carried out on the same instrument with the same column as described above. The injection volume was $10 \mu \mathrm{L}$, and detection was carried out at $425 \mathrm{~nm}$. In order to quantify the amount of celastrol in extracts, calibration curves were prepared with the standards dissolved in methanol. The calibration curves showed good linearity from 10.0 to $200.0 \mu \mathrm{g} / \mathrm{mL}$ 


\subsubsection{Wilforine}

Wilforine content of the crude extract was determined by HPLC, as described previously with some modifications [19]. Extract (50 mg) was dissolved in chloroform $(5 \mathrm{~mL})$ and loaded on a column packed with neutral $\mathrm{Al}_{2} \mathrm{O}_{3}(2.0 \mathrm{~g})$. Elution was with ethyl acetate $(20 \mathrm{~mL})$. The eluate was evaporated under reduced pressure, and re-dissolved in methanol $(5.0 \mathrm{~mL})$. Samples were filtered through a $0.22 \mu \mathrm{m}$ membrane filter for HPLC. The HPLC analysis was carried out on the same instruments with the same column as described above. The injection volume was $10 \mu \mathrm{L}$, and detection was carried out at $210 \mathrm{~nm}$. In order to quantify the amount of wilforine in extracts, calibration curves were prepared with the standards dissolved in methanol. The calibration curves showed good linearity over 5.1-68.0 $\mu \mathrm{g} / \mathrm{mL}$ range.

\subsection{Cytotoxicity and Anti-inflammatory Activity of the Extracts}

The extracts were assessed for cytotoxicity and antiinflammatory activity as described above.

\subsection{Assessment of Acute Toxicity}

We first assessed the range of doses of Extracts 1 that caused $0 \%$ and $100 \%$ deaths in mice using a pre-test. Fifty BALB/c mice were randomly divided into five groups (five female mice and five male mice each). Each group was administered orally different doses of Extract 1 at 725.8, 1,209.6, 2,016, 3,360 and $5,600 \mathrm{mg} / \mathrm{kg}$ body weight. After administration, all external morphological, behavioral, neurological and autonomic changes, number of deaths and time to death, as well as some other toxic effects were recorded continuously at $1 \mathrm{~h}$ intervals over a period of $24 \mathrm{~h}$. According to the mortality of mice observed within one week, the $\mathrm{LD}_{50}$ values ( $95 \%$ confidence interval) for Extract 1 was calculated using BSAS110 software (National Institute for the Control of Pharmaceutical and Biological Products, Beijing, China) with the Bliss method.

\subsection{Statistical Analysis}

Experimental data were expressed as means \pm SD. Results were analyzed by an analysis of variance (ANOVA) $(p<0.05)$ and means separated by Duncan's test. Statistical analysis was performed using SAS program 8.2 software (SAS Institute Inc., Cary, NC, USA).

\section{Conclusions}

The results of this study showed that removal of the acidic components of Tripterygium using sodium carbonate extraction greatly reduced its cytotoxicity. Further acute toxicity tests confirmed that Extract 1 had the lowest toxicity and therefore could represent a potential source of raw medicine material for clinical application.

\section{Acknowledgements}

The authors thank The Science and Technology Development Fund of the Macau Special Administrative Region for financial support (Project No. 040/2009/A2). 


\section{References}

1. The Editorial Board of Chinese Materia Medica of State Administration of Traditional Chinese medicine of P. R. China. Chinese Materia Medica; Shanghai Scientific \& Technical Publishers: Shanghai, China, 1999; Volume 5, pp. 206-215.

2. Tao, X.; Lipsky, P.E. The Chinese anti-inflammatory and immunosuppressive herbal remedy Tripterygium wilfordii Hook.f. Rheum. Dis. Clin. N. Am. 2000, 26, 29-50.

3. Qiu, D.; Peter, N.K. Immunosuppressive and anti-Inflammatory mechanisms of triptolide, the principal active diterpenoid from the chinese medicinal herb Tripterygium wilfordii Hook. F. Drugs $R \& D$ 2003, 4, 1-18.

4. Li, L.S.; Liu, Z.H. Experience of triptolide treatment of nephritis in twenty-five years. Chin. J. Nephrol. Dial. Transplant. 2003, 12, 246-247.

5. Zheng, C.X.; Chen, Z.H.; Zeng, C.H.; Qin, W.S.; Li, L.S.; Liu, Z.H. Triptolide protects podocytes from puromycin aminonucleoside induced injury in vivo and in vitro. Kidney Int. 2008, 74, 596-612.

6. Sun, X.; Zhang, S.M.; Tian, C.H.; Yang, L.; Wang, L.M.; Li, S.L. Safety of Tripterygium wilfordii. Chin. J. New Drugs 2001, 10, 539-543.

7. Zhang, Q.P.; Song, H.T. The study on Preparations of TWHF. China Pharm. 2009, 12, 881-883.

8. Gao, X.; Song, M.; Zhuang, Y.; Zhai, Q.B.; Hang, T.J.; Ma, P.C. Study of Tripterygium wilfordii Hook. F. and Tripterygium wilfordii preparations by HPLC specific chromatograms. Chin. J. Pharm. Anal. 2009, 29, 702-709.

9. Brinker, A.M.; Ma, J.; Lipsky, P.E.; Raskin, I. Medicinal chemistry and pharmacology of genus Tripterygium (Celastraceae). Phytochemistry 2007, 68, 732-766.

10. Salminen, A.; Lehtonen, M.; Paimel, T.; Kaarniranta, K. Celastrol: Molecular targets of Thunder God Vine. Biochem. Bioph. Res. Commun. 2010, 394, 439-442.

11. Liu, Q.Y. Triptolide and its expanding multiple pharmacological functions. Int. Immunopharmacol. 2011, 11, 377-383.

12. Li, H.R.; Li, S.F.; Duan, H.Q.; Zhou, W.; Tian, S.J. Process optimization of supercritical fluid extraction of active components in Tripterygium Wilfordii Hook.f. J. Tianjin Univ. 2007, 40, 269-274.

13. Zheng, J.R.; Gu, K.X.; Xu, L.F.; Gao, W.J.; Yu, Y.H.; Tang, M.Y. Screening of active anti-inflammatory, immunosuppressive and antifertility components of Tripterygium wilfordii. III. A comparison of the anti-inflammatory and immunosuppressive activities of 7 diterpene lactone epoxide compounds in vivo. Acta Acad. Med. Sin. 1991, 13, 391-397.

14. Zhu, X.M.; Xiong, R.C.; Zhang, Y.F.; Zhang, Y.K. Studies on immunosuppresive effect of tripterine monomer on renal transplant mongrel dogs. Chin. J. Organ Transplant. 1996, 17, $21-22$.

15. Zhou, J.L.; Zhu, Q.; Yang, X.L.; Zhang, F. Clinical observation of side effects of Tripterygium preparation. Chin. J. Integr. Med. 1999, 19, 77-79.

16. Li, L.Y.; Jin, R.M.; Li, Y.K.; Fu, S.G.; Huang, J.; Zhu, Z.L.; Zhang, J.H. Study immunosuppressive effect and safety Tripterygium glycosides by multiple doses. Chin. J. New Drugs Clin. Rem. 2006, 25, 248-251. 
17. Chi, Y.M.; Wen, H.M.; Xu, J.G. Determination of content of triptolide in Tripterygium wilfordii herbal pieces with HPLC method. J. Nanjing Univ. Tradit. Chin. Med. Nat. Sci. 2001, 17, 32-33.

18. Ku, E.; Zhang, Y. Determination of content of celastrol in Tripterygium wilfordii herbal pieces with HPLC method. Northwest Pharmaceut. J. 2008, 23, 82-84.

19. Huang, W.H.; Zhang, R.; Guo, B.L.; Si, J.P. Study on total alkaloids content and its influential factors in medicinal materials of Tripterygium. China J. Chin. Materia Med. 2008, 33, 15-18.

Sample Availability: Samples of the Triptolide, Celastrol and Wilforine are available from the authors.

(C) 2012 by the authors; licensee MDPI, Basel, Switzerland. This article is an open access article distributed under the terms and conditions of the Creative Commons Attribution license (http://creativecommons.org/licenses/by/3.0/). 